\title{
Central Diabetes Insipidus as the Inaugural Manifestation of Langerhans Cell Histiocytosis in Adult
}

Achour TB ${ }^{1}$, Sayhi $\mathbf{S}^{* 1}$, Achoura $\mathbf{S}^{1}$, Salah HM$^{1}$, Sakni IM², Ajili $\mathrm{F}^{1}$ and Louzir $\mathrm{B}^{1}$

${ }^{1}$ Internal Medecine Department, Military Hospital of Tunis, Tunisia

${ }^{2}$ Anatomopathology Department, Military Hospital of Tunis, Tunisia

*Corresponding author: Sayhi S, Internal Medecine Department, Military Hospital of Tunis, Tunisia, Tel: 71560 244; E-mail: sameh_sayhi@yahoo.fr

Received date: September 19, 2018; Accepted date: September 24, 2018; Published date: September 28, 2018

Copyright: (๑) 2018 Achour TB, et al. This is an open-access article distributed under the terms of the Creative Commons Attribution License, which permits unrestricted use, distribution, and reproduction in any medium, provided the original author and source are credited.

\begin{abstract}
Langerhans histiocytosis $(\mathrm{LH})$ is a rare disease that is more prevalent in children. Adult onset $\mathrm{LH}$ is less observed. Its etiology still remains unclear. Bone involvement is the most frequent. Other organs involvement such as pulmonary, pituitary and cutaneous is rarer. Diagnosis confirmation relies on histological examination. It highlights the accumulation of Langerhans cells organized as granulomas with positive immunohistochimical staining for CD1a. Optimal treatment choices are still undefined. It depends whether it involve a single system or is a multisystem form with life-threatening organ involvement. Treatment is based on corticosteroids and Vinblastine associated with possibly resorting to surgery in some cases.
\end{abstract}

In this report, we present the case of a male patient who developed multisystem LH (MS-LH) with multiple bone lesions, pulmonary involvement and pituitary infiltration. This patient was successfully treated by local surgical curettage and adjuvant corticoids therapy.

Keywords: Langerhans histiocytosis; Central diabetes insipidus; Computed tomography; Histiocytes

\section{Introduction}

LH is a rare disease characterized by clonal proliferation of CD1a+ histiocytes. It may present as single (SS-LH) or multisystem (MS-LH) involvement disease. The definition of MS-LH is the LH with two or more organs/systems involvement. It is usually associated with poorer prognosis and a faster impairment than in SS-LCH [1]. LH is less frequent in adult than it is in children; it has some specific features and poses distinct therapeutic challenges. We report the case of a patient presenting LH with multisystem involvement.

\section{Case Report}

27-year-old male, with a36 pack-year history of smoking, was admitted in our internal medicine department for progressive hearing loss and painless swelling of the left temple. The patient had been diagnosed with central diabetes insipidus 3 years ago as he presented polydipsia and polyuria. Cerebral magnetic resonance imaging (MRI) showed pituitary infiltration with nonspecific hypophysitis. He was treated using corticosteroids at $1 \mathrm{mg} / \mathrm{kg} /$ day for one month with progressive tapering for a total duration of 2 years associated with Desmopressin. Clinical and radiological course was favorable and then patient was lost to follow-up. His recent complaints started three months prior to his hospitalization. He did not report recurrence of polydipsia and polyuria.

Physical examination revealed a painless swelling of the left temple of hard consistency with no local inflammation signs. Neurological examination showed left hemifacial hypoesthesia. His vital signs were stable. Neither bone pain nor skin lesions were detected.

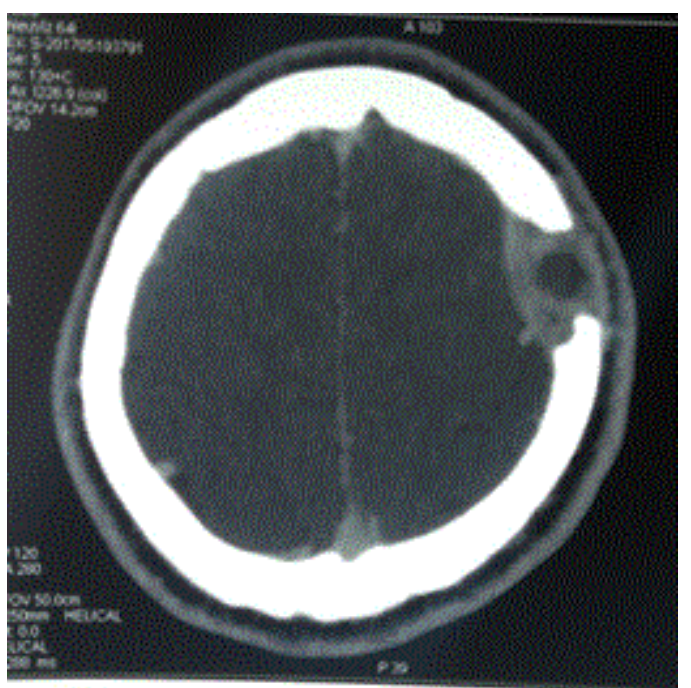

Figure 1: Coronal computed tomography image showing an expansive process centered on the left temporal bone.

There was no laboratory evidence of inflammation, C-reactive protein level was $3 \mathrm{mg} / \mathrm{dL}$ and erythrocyte sedimentation rate was 34 mmHg. Full blood count was normal. Phosphate-calcium balance and liver function tests were within normal range. Prolactin serum level was two times higher than laboratory range at $418 \mathrm{mU} / \mathrm{l}$. Hypothalamic pituitary adrenal, thyroid and somatotropic axes exploration did not reveal other abnormalities. Cerebral and temporal bone computed tomography (CT) showed an expansive process centered on the left temporal bone and the mandibular fossa extending 
Citation: Achour TB, Sayhi S, Achoura S, Salah HM, Sakni IM, et al. (2018) Central Diabetes Insipidus as the Inaugural Manifestation of Langerhans Cell Histiocytosis in Adult. J Cytol Histol 9: 521. doi:10.4172/2157-7099.1000521

to the roof of the glenoid fossa of the temporomandibular joint and invading the joint space. It also revealed a tissular mass of the left parietal convexity with subcutaneous tissues infiltration and contrast uptake of meninges in the same area (Figures 1 and 2). Surgical excision of the tumoral processes was performed.

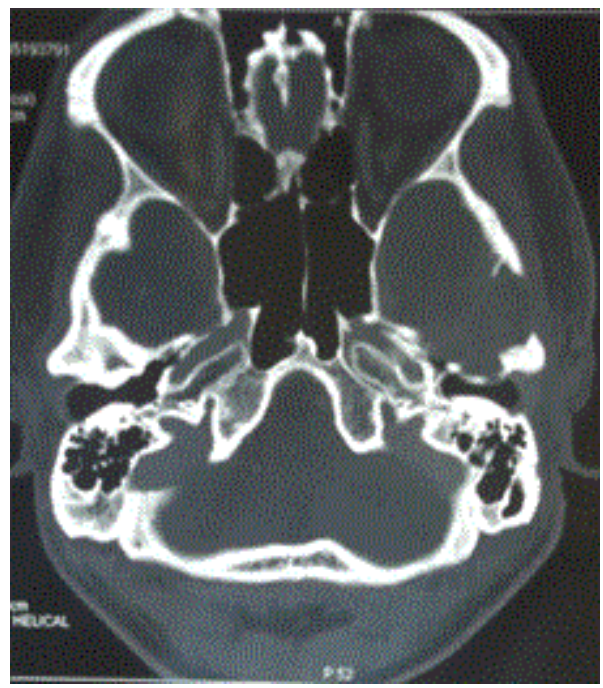

Figure 2: Sagittal computed tomography image showing the mandibular fossa extending to the roof of the glenoid fossa of the temporo-mandibular joint and invading the joint space.

Histological examination showed granulomas with large histiocytes cells having irregular nuclei. At immunohistochimical staining Langerhans' cells diffused strong positivity for S-100, and CD1a. These aspects were highly concordant with the diagnosis Langerhans histiocytosis (Figures 3 and 4).

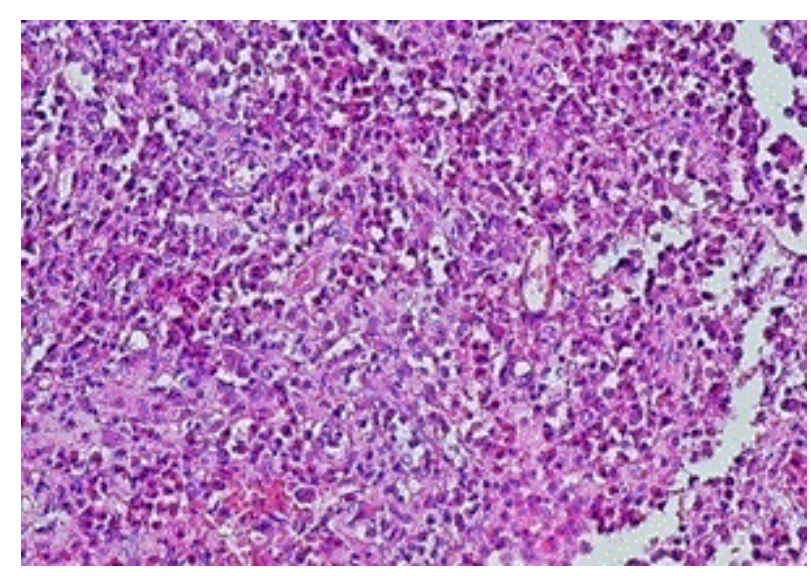

Figure 3: Hematoxylin Eosin stainingx400: cell proliferation made of histocytes and Eosinophilic Plynuclear cells.

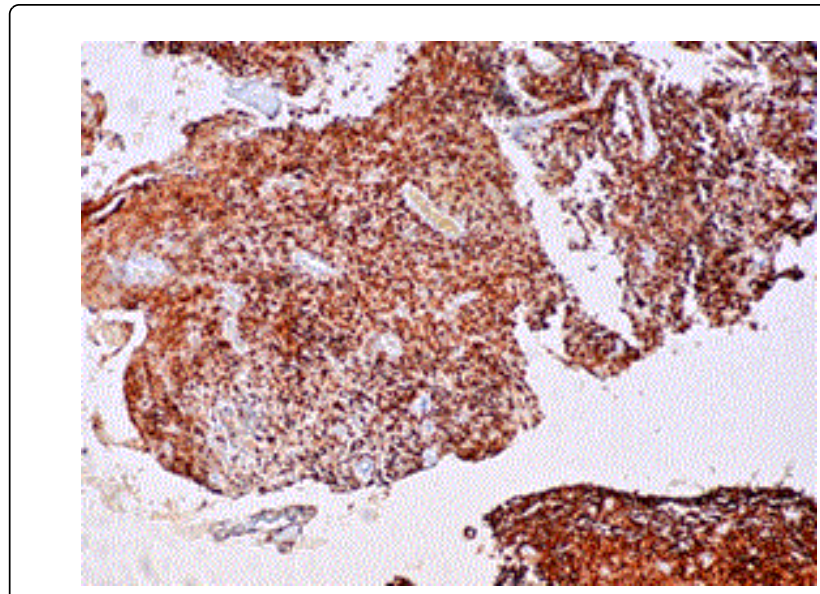

Figure 4: immunohistochemistry CD1Aa x250: intense and diffuse cytoplasmic positivity.

Bone scan revealed increased radioisotope uptake on the skull, the seventh costovertebral junction, the right scapula and the left hemipelvis. Chest CT scan objectified bilateral peripheral cystic pulmonary lesions. Given the multisystem involvement, patient was put on Prednisone at a dose of $1 \mathrm{mg} / \mathrm{kg} / \mathrm{day}$ for one month followed by progressive tapering associated with Vinblastine. After three months of treatment chest CT scan partial regression of cystic pulmonary lesions while bone scan noted stable bone lesions.

\section{Discussion}

Langerhans cell histiocytosis ( $\mathrm{LH})$ is a rare disease with uncertain etiology. It is characterized by the infiltration of one or more organs by Langerhans cell-like dendritic cells, most often organized in granulomas. This disease is also known as histiocytosis $\mathrm{X}$, eosinophilic granuloma, Hand-Schuller-Christian disease, Abt-Letterer-Siwe disease, Hashimoto-Pritzker disease, and Congenital self-healing reticulohistiocytosis. $\mathrm{LH}$ incidence is higher in infants (15.3 cases per million), and decreases with age to reach 2 permillion after 10 years [2].

LH cause remains unknown to date and the nature of this condition remains debated whether it is neoplastic or secondary to a dysimmune reaction. In LH, CD1a+ histiocytes have an abnormal, semi mature phenotype [3]. The recent discovery of the high prevalence of a mutation V600 Einthe BRAF oncogene and the constant involvement of the RAS-RAFMEK-ERK pathway is an important step forward in understanding the disease [4]. Since then, it has been shown that this somatic oncogenic mutation was present in 38 to $60 \%$ of $\mathrm{LH}$. This mutation is found in various types of solid cancers, particularly melanomas $(>50 \%)$, papillary thyroid cancers $(60 \%)$, and more rarely colorectal or pulmonary cancers. It is found in $100 \%$ of hairy cell leukemia cases [3].

The clinical presentation of LH is highly variable. Bone, skin, pituitary gland, lung, central nervous system, lymphoid organs are mainly involved.

Bone involvement is the most frequent and represents up to $50 \%$ of the disease localizations in the adult. It can be single or multiple lesions and may occur within the same bone. It predominates at the cephalic and axial bones [5]. The most frequent reported skeletal invasion sites 
are the skull (29.9\%), proximal femur (12.4\%), and ribs (11.1\%) [6]. Our patient had multiple bone lesions: skull, costovertebral junction, scapula and pelvis all of which were asymptomatic and detected by bone scintigraphy. However, he had hypoacusia related to an extension of the tumor process to the middle ear. This needs to be differentiated from otitis externa, which may also manifest as auricular discharge, because of the extension of cutaneous lesions to the auditory canal. Hand-Schüller-Christian is characterized by cranial bone deficiencies, exophthalmia and diabetes insipidus which is similar to our patient condition and multiple bone lesions with local extension, meningeal and peri-orbital lesions direct can be noted. Our patient had multiple bone involvement, meningeal lesions and diabetes insipidus but did not exhibit exophthalmia and histological examination was in favor of $\mathrm{LH}$. Soft tissue involvement in the cranial oraxial regions appears to be more common in adults than children and associated with an increased risk of relapse like our case [3].

Pituitary involvement may be suspected in case of polyuria and polydipsia. In adult-onset LH studies, incidence of central diabetes insipidus varies from 15 to $30 \%$ [6]. Post-pituitary gland involvement is common and may precede the diagnosis of HL. Our patient had post-pituitary gland infiltration revealed by polyuria and polydipsia. Involvement of the anterior pituitary gland is also possible, sometimes going as far aspan-hypopituitarism.

Our patient had bilateral cystic pulmonary lesions that were asymptomatic. In fact, in 10 to $25 \%$ of cases; pulmonary involvement is asymptomatic. It must be noted however that it is associated in more than $90 \%$ to smoking [3] such as our patient. Various lung lesions can be observed: solid nodules, excavated nodules, thick-walled cysts and thin-walled cysts. Pulmonary lesions evolution is unpredictable. It can be towards stabilization oron the contrary, a gradual and sometimes rapid aggravation can occur up to chronic respiratory failure stage.

Cutaneous involvement can be single or multifocal. Skin lesions usually take the form of scaly or crusted papules or brown/red nodules that can be ulcerated [5]. The most frequent sites are the trunk, the face and the scalp. Involvement of the external auditory canal and the retroauricular groove are indicative. Large folds, perianal and vulvar involvement is common in adults and can be very debilitating. Oral ulcerations and periodontal destruction with dental loss can also be observed.

As for hematological involvement, it seems rare in adults (less than $5 \%$ in Kilpatrick et al study) [3]. However, it can be life threatening. It usually present as pancytopenia associated with hepatomegaly and splenomegaly. It can be difficult to differentiate form malignant hematological disease especially as HL has been reported to transform into monocytic leukemia [3]. Lymph nodes involvement may occur in that receiving direct lymph drainage from cutaneous and bone lesions [3].

Exceptionally, digestive tract involvement has been reported. It manifests as diarrhea and malabsorption syndrome [7]. Our patient did not present signs of digestive or hematological involvement.

Systematic treatment in adults is not consensual, and varies according to country and habits of the centers. Very few studies quantify its effectiveness and tolerance. Many drugs are used in LH: nonsteroidal anti-inflammatory drugs (NSAIDs), corticosteroids, cytostatic drugs such as Vinblastine, Etoposide, 6-mercaptopurine, methotrexate, cytarabine and cladribine (2Cda), interferon alpha, antiTNF-alpha, ciclosporin A, thalidomide and various other drugs such as imatinib, retinoids and bisphosphonates. In France, first line treatment of multisystem LH is usually based on the association Vinblastine corticosteroids. In the International Register published in 2003, this association was also most often used as first line treatment [8]. This combination is indicated during hepatic, hematopoietic splenic involvement and for skeletal, pulmonary and neurological disorders with functional impact. The evaluation of the response to treatment is done by an activity score of the disease [9]. In case of failure $2 \mathrm{Cda}$ is used. It's mainly indicated in refractory forms and if activity score is higher than five [10].

In the future, new targeted therapies, such as Vemurafenib, could come to enrich the therapeutic arsenal since half HL patients present the V600E BRAF mutation.

\section{Conclusion}

Adult onset Langerhans histiocytosis is not exceptional but remains little studied and our knowledge is still based essentially on the extrapolation of pediatric cases. Future studies seem interesting to gain more insight in the characteristics of such disease and to devise efficient treatment.

\section{Competing Interests}

The authors declare no competing interest.

\section{References}

1. Pierro J, Vaiselbuh SR (2016) Adult Langerhans cell histiocytosis as a diagnostic pitfall. J Clin Oncol 34: 41-45.

2. Guyot-Goubin A, Donadieu J, Barkaoui M, Bellec S, Thomas C, et al. (2008) Descriptive epidemiology of childhood Langerhans cell histiocytosis in France, 2000-2004. Pediatr Blood Cancer 51: 71-75.

3. Néel A, Artifoni M, Donadieu J, Lorillon G, Hamidou M, et al. (2015) Langerhans cell histiocytosis in adults. Rev Med Interne 36: 658-667.

4. Aricò M, Girschikofsky M, Généreau T, Klersy C, McClain K, et al. (2003) Langerhans cell histiocytosis in adults. Report from the International Registry of the Histiocyte Society. Eur J Cancer 39: 2341-2348.

5. Oehler E, Léogite J, Hellal K, Feuillet B, Evenat F, et al. (2014) Bone lesions. Rev Med Interne 35: 554-555.

6. Howarth DM, Gilchrist GS, Mullan BP (1999) Langerhans cell histiocytosis: diagnosis, natural history, management, and outcome. Cancer 85: 2278-2290.

7. Généreau T, Klersy C, McClain K, Grois N (2003) Langerhans cell histiocytosis in adults. Report from the International Registry of the Histiocyte Society. Eur J Cancer 39: 2341-2348.

8. Donadieu J, Héritier S (2017) Histiocytose langerhansienne de l'enfant. Presse Med 46: 85-95.

9. Badalian-Very G, Vergilio JA, Degar BA, MacConaill LE, Brandner B, et al. (2010) Recurrent BRAF mutations in Langerhans cell histiocytosis. Blood 116: 1919-1923.

10. Donadieu J, Piguet C, Bernard F, Barkaoui M, Ouache M, et al. (2004) A new clinical score for disease activity in Langerhans cell histiocytosis. Pediatr Blood Cancer 43: 770-776. 